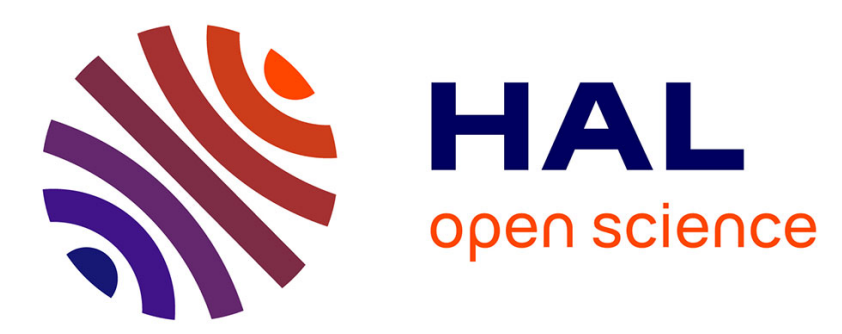

\title{
Electrochemical behavior of pure graphite studied with a powder microelectrode
}

\author{
David Gruet, Bruno Delobel, David Sicsic, Ivan T. Lucas, Mireille Turmine, \\ Vincent Vivier
}

\section{> To cite this version:}

David Gruet, Bruno Delobel, David Sicsic, Ivan T. Lucas, Mireille Turmine, et al.. Electrochemical behavior of pure graphite studied with a powder microelectrode. Electrochemistry Communications, 2018, 95, pp.23 - 27. 10.1016/j.elecom.2018.08.016 . hal-01868434

\section{HAL Id: hal-01868434 \\ https://hal.sorbonne-universite.fr/hal-01868434}

Submitted on 5 Sep 2018

HAL is a multi-disciplinary open access archive for the deposit and dissemination of scientific research documents, whether they are published or not. The documents may come from teaching and research institutions in France or abroad, or from public or private research centers.
L'archive ouverte pluridisciplinaire HAL, est destinée au dépôt et à la diffusion de documents scientifiques de niveau recherche, publiés ou non, émanant des établissements d'enseignement et de recherche français ou étrangers, des laboratoires publics ou privés. 


\title{
Electrochemical behavior of pure graphite studied with a powder microelectrode
}

\author{
David GRUET ${ }^{a}$, b , Bruno DELOBEL ${ }^{a}$, David SICSIC ${ }^{a}$, Ivan T. LUCAS ${ }^{b}$, \\ Mireille TURMINE ${ }^{b}$, Vincent VIVIER ${ }^{b}{ }^{*}$ \\ ${ }^{a}$ Technocentre Renault, 1 avenue du Golf, 78288 Guyancourt, France \\ ${ }^{b}$ Sorbonne Université, CNRS, Laboratoire Interfaces et Systèmes Electrochimiques, LISE, F-75005 \\ Paris, France
}

\section{vincent.vivier@upmc.fr}

\begin{abstract}
In this work, cyclic voltammetry and electrochemical impedance spectroscopy (EIS) techniques have been used to study the lithiation/delithiation of graphite using powder microelectrode in a 1.2 $\mathrm{M} \mathrm{LiPF}_{6}$ in EC:EMC electrolyte. The advantage of using the powder microelectrode is the possibility to easily study graphite without any additive and determine electrochemical characteristic of Li-insertion. The use of cyclic voltammetry at very low scan rates allows to estimate the diffusion coefficient of lithium inside graphite. The exchange current density of graphite for several state of charge (SoC) has also been determined by EIS measurements. Moreover, the powder microelectrode is a useful tool to study the formation of the solid electrolyte interphase (SEI) on graphite whether by cyclic voltammetry or EIS.
\end{abstract}

Keywords: Graphite, battery material, cavity microelectrode, cyclic voltammetry, Li-ion battery 


\section{Introduction}

Due to its low cost and relatively high gravimetric capacity $\left(372 \mathrm{mAh} \mathrm{g}^{-1}\right)$, graphite has been widely studied for lithium-ion battery applications as an efficient candidate for negative electrode material [1]. The intercalation of lithium inside the graphite is a reversible process occurring at low potentials vs $\mathrm{Li}$, and a detailed investigation of the kinetics of this process remains challenging. Indeed, electrodes in battery systems usually consist in a composite porous electrode, that is for the negative electrode, a mixture of electroactive graphite, conductive carbon and of a polymer binder. As a result, the electrochemical response of the composite electrode is no longer the electrochemical response of the active material itself, thus requiring to develop techniques for studying the active material separately. Interestingly, several techniques have been devised for studying the active material only (i.e. without any additive), and most of them required the use of microelectrode-based techniques [2-4]. Indeed, it consists in contacting a single particle of material with a current collector and to perform electrochemical measurements on the selected grain. With such a technique, Nishizawa et al. $[5,6]$ reported on the electrochemical response of a mesocarbon single particle pressed against a $\mathrm{Ni}$ band microelectrode. The study of Li insertion inside graphitized carbon [7] and disordered carbon [8] by means of electrochemical impedance spectroscopy (EIS) has also been performed. Similarly, Positive electrode materials have been studied such as $\mathrm{LiMn}_{2} \mathrm{O}_{4}[9-12]$ or $\mathrm{LiCoO}_{2}[9,10,13,14]$. In particular, kinetic characterizations of $\mathrm{LiMn}_{2} \mathrm{O}_{4}$ [11] and $\mathrm{LiCoO}_{2}$ [14] particles have been realized where the diffusion coefficient of lithium inside the material have been estimated by Potential Steps methods and EIS.

Another approach for studying pure battery materials is the powder microelectrode also called the cavity microelectrode [15-21]. This technique consists in inserting a small amount of material (still without any additive) inside a micrometer-sized cavity to perform electrochemistry on few grains. Interestingly, compared to the single particle technique, it does not require to work under a microscope for connecting the grain to the current collector, and hundreds of cycles can be readily performed as illustrated on polyaniline [17] and hydride materials [22]. Li-insertion battery materials powders such as $\mathrm{V}_{2} \mathrm{O}_{5}$ [21], $\mathrm{LiMn}_{2} \mathrm{O}_{4}$ [16], a mixture of $\mathrm{LiMn}_{2} \mathrm{O}_{4}$ with graphite 
[20] or a mixture of $\mathrm{LiFePO}_{4}$ with conductive carbon [19] have been successfully studied electrochemically (CVs) using a cavity microelectrode.

The aim of this work is to show that it is possible to use a cavity microelectrode for studying Li insertion in graphite powder without the adjunction of conductive carbon or any binder, which has never been realized before. Our choice was directed towards the cavity microelectrode technique rather than the single particle measurement for several reasons. Performing electrochemical tests on a single particle requires specific equipment, the contact between the particle and the microelectrode is tedious because of the swelling of the material upon lithiation, and a current in the pA range or less for performing efficient charge/discharge cycles is very small. With a cavity microelectrode, no special equipment is required, the contact would not depend on the swelling and the currents are sufficiently high (in the nA range or larger) for cycling the material. In this work, the insertion/deinsertion of lithium inside the graphite particles is investigated by cyclic voltammetry and EIS at different insertion ratio.

\section{Experimental}

The insertion/deinsertion reactions of Li in graphite were investigated using a home-made cavity microelectrode $[17,18]$. Most of the results presented in the literature consisted in using a Pt microwire sealed by heating in a borosilicate glass capillary. The extremity of the wire was then dissolved in order to form a microcavity, in which the material was inserted. For studying graphite, platinum is not a good candidate as current collector since it alloys with Lithium. It was thus advantageously replaced by a copper microwire (150 $\mu \mathrm{m}$ in diameter), which was inserted inside a capillary glass and sealed at the bottom with an epoxy resin. The microelectrode was then polished using sandpaper (P4000), exposing a copper microdisk at the apex of the electrode. In a last step, the cavity was obtained by anodic dissolution of copper in a $1 \mathrm{M} \mathrm{KCl}$ solution. The depth of the cavity was controlled with the duration of the dissolution and checked with optical observations. The cavity is then filled by pressing the electrode against graphite powder (Fig. 1a). All electrochemical measurements were performed in a three-electrode configuration (Fig. 1b) using a cavity microelectrode as working electrode and two Li metal strips as counter and reference electrode, respectively. 
The graphite powder was provided by POSCO. Its active surface area was about $3 \mathrm{~m}^{2} / \mathrm{g}$ and the average particle size obtained from SEM observations was $15 \mu \mathrm{m}$ in diameter (vide infra). The electrolyte consisted in a 1.2 $\mathrm{M} \mathrm{LiPF}_{6}$ in an EC:EMC (3:7 vol.) mixture. The cell was assembled in an argon-filled glovebox (oxygen and water content below $1 \mathrm{ppm}$ ). All the electrochemical experiments were performed in the glovebox using a GAMRY REF 600+ potentiostat. Before each experiment, cavity was cleaned by sonication in a water/ethanol mixture (1:1 vol.) for 15 minutes.

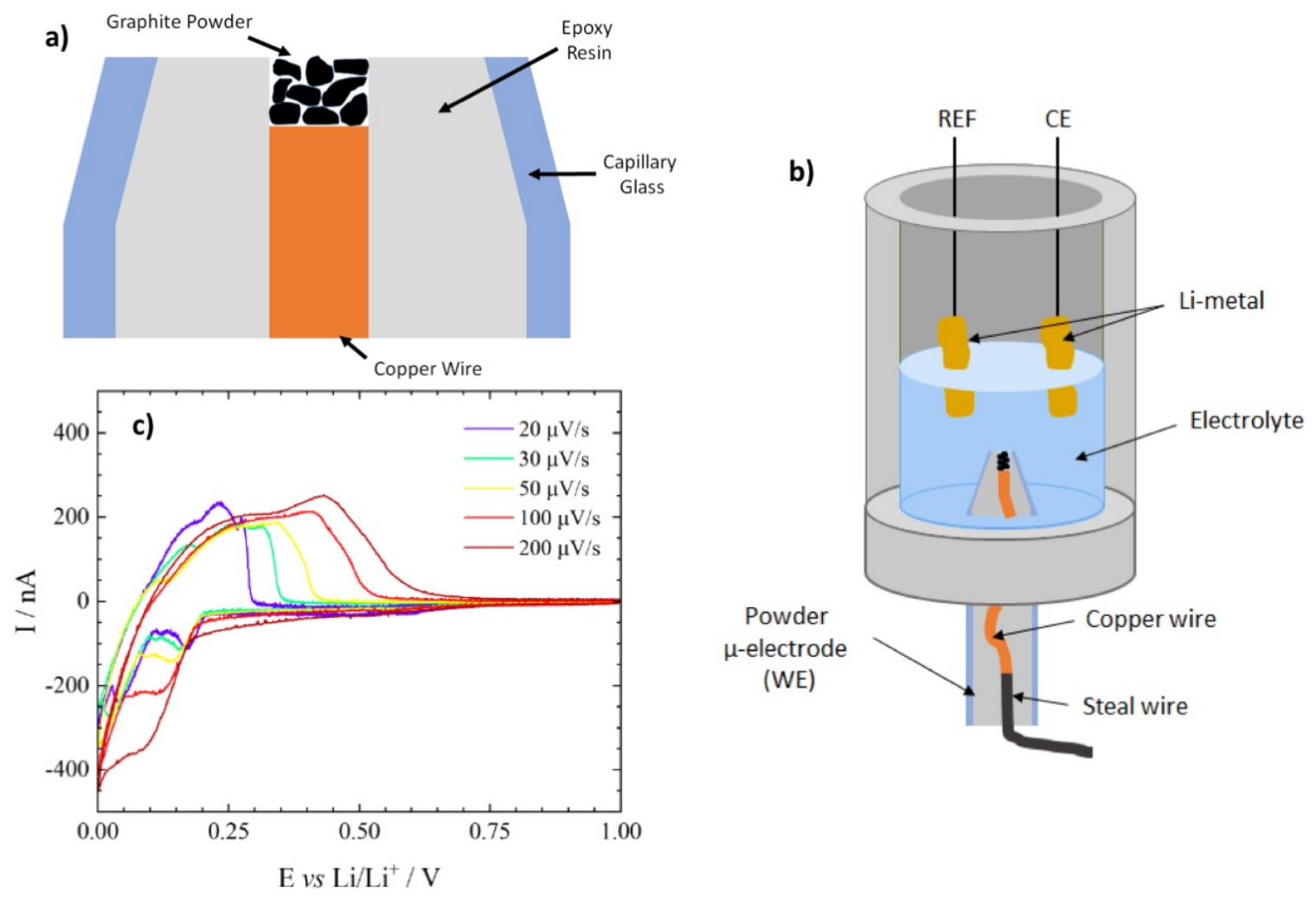

Figure 1. (a) Schematic representation of the powder microelectrode; (b) Experimental set-up where the powder microelectrode is immersed in a 1.2M LiPF 6 EC:EMC (3:7 vol.) electrolyte trapped in a Teflon cell; (c) Cyclic voltammetry performed on the powder microelectrode as a function of the scan rate.

\section{Results and Discussions}

- Cyclic voltammetry experiments 
The electrochemical kinetics of lithiation / delithiation processes of graphite was first studied by cyclic voltammetry starting from $1 \mathrm{~V} / \mathrm{Li} / \mathrm{Li}^{+}$at several scan rates (Fig. 1C). During the reduction scans, a small shoulder followed by a plateau is observed at $c a .0 .6 \mathrm{~V} / \mathrm{Li}^{\prime} \mathrm{Li}^{+}$. This irreversible process is ascribed to the formation of a passivating layer, the solid electrolyte interphase (SEI), around the particles and is observed for the first cycles, only. At lower potentials, the staging for lithium insertion at different potentials between 0.2 and $0 \mathrm{~V} / \mathrm{Li}^{\prime} \mathrm{Li}^{+}$corresponding to peaks more or less well-defined, can be identified. When the scan rate increases from 20 to $200 \mu \mathrm{V} / \mathrm{s}$, the contribution to the SEI formation gradually decreases with the cycle number, and we clearly see a polarization phenomenon, which reflects the electrochemical response by both an enlargement and an overlapping of the insertion peaks. Similarly, on the oxidation domain, the delithiation of graphite particles resulted in a multi-steps processes, with an increase of the overpotential with the scan rate.

When the cyclic voltammetry was performed at $20 \mu \mathrm{V} / \mathrm{s}$ (blue curve in Fig. 1c), two insertion peaks are well defined. However, for potential lower than $50 \mathrm{mV} / \mathrm{Li}^{\prime} \mathrm{Li}^{+}$, a strong increase of the reduction current is observed, and a fine analysis of the electrochemical signal is no longer possible.

By decreasing the scan rate at $5 \mu \mathrm{V} / \mathrm{s}$ (Fig. 2a), we approach the steady-state behavior, allowing a better visualization of all the individual stages for lithium insertion inside the graphite flakes. During the reduction scan, the small shoulder followed by a plateau of about - $6 \mathrm{nA}$ corresponding to the SEl formation is observed, thus shifting the whole profile of the CV to negative values for the first cycle. The comparison of SEM images presented in Figs. 2(c-e) confirms that SEI has been formed around the particles. It should be noted that the surface roughness of the epoxy resin (Fig.2b) is the one observed straight after polishing whereas the surface roughness shown in Fig. $2 \mathrm{c}$ is ascribed to the multiple uses of the powder microelectrode (loading, testing and cleaning) without any polishing between experiments.

Then, three main insertion peaks of lithium inside the graphite are observed at $200 \mathrm{mV} / \mathrm{Li}^{2} \mathrm{Li}^{+}$, $98 \mathrm{mV} / \mathrm{Li}^{\mathrm{Li}}{ }^{+}$and $56 \mathrm{mV} / \mathrm{Li} / \mathrm{Li}^{+}$. On Fig. 2a, the vertical dashed lines separate the phases of graphite with lithium intercalation. Each peak corresponds to the co-existence of two phases 
except the small peak at ca. $160 \mathrm{mV} / \mathrm{Li} / \mathrm{Li}^{+}$(labelled 3+4) which refers to a solid solution domain [23]. With the use of powder microelectrode at very low scan rate, the « real " potentials of pure graphite phase transitions are obtained, thus limiting percolation problems that can be encountered in presence of additives.
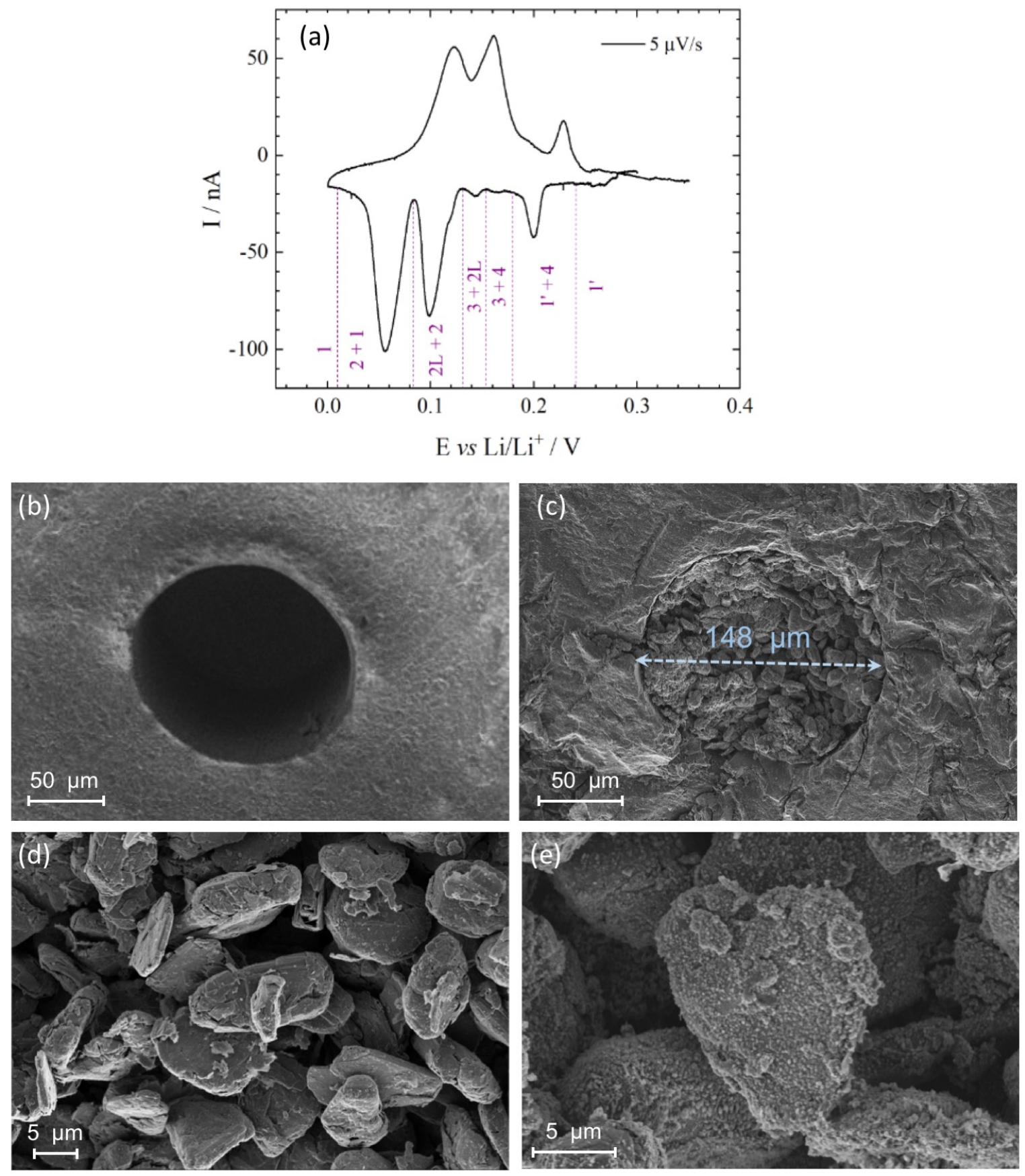

Figure 2. (a) CV curve performed at $5 \mu \mathrm{V} / \mathrm{s}$ with the powder microelectrode on graphite; (b) SEM image of an empty powder microelectrode; (c) SEM image of the powder microelectrode filled of graphite particles after cycling; (d) SEM image of the particles 
before cycling; (e) SEM image of the particles after cycling - SEI film can be seen around the particles (the microelectrode has been previously washed with DEC).

Since the amount of material initially inserted in the cavity is unknown, it can be determined from the exchanged charge calculated from the CV curves obtained at the lowest scan rate (CV curve at $5 \mu \mathrm{V} / \mathrm{s}$ - Fig. 2a), assuming that all the graphite particles have been fully lithiated. For a mean dimension of $(15 \times 8 \times 1) \mu \mathrm{m}^{3}$ for the particle size (Fig. $\left.2 \mathrm{~d}\right)$, a total number of about 4000 particles inside the cavity was obtained. Assuming a double layer capacitance of $10 \mu \mathrm{F} / \mathrm{cm}^{2}$ [24], this value is in fair agreement with EIS measurement performed on delithiated graphite which allows counting 3800 particles. This corresponds to a filling of about $65 \%$ of the cavity.

Additionally, the diffusion coefficient of lithium can be determined for each lithiated graphite phase using the Randles-Sevcik's equation. From the graphite load determined previously, the specific area of graphite inside the cavity was calculated, thus leading to $D_{1}=1.22 \times 10^{-14} \mathrm{~m}^{2} /$ $s, D_{2}=1.93 \times 10^{-14} \mathrm{~m}^{2} / \mathrm{s}$ and $D_{3}=1.29 \times 10^{-14} \mathrm{~m}^{2} / \mathrm{s}$ for the peaks at $200 \mathrm{mV} / \mathrm{Li}^{\prime} \mathrm{Li}^{+}$, $98 \mathrm{mV} / \mathrm{Li} / \mathrm{Li}^{+}$and $56 \mathrm{mV} / \mathrm{Li} / \mathrm{Li}^{+}$, respectively. Interestingly, the diffusion coefficient for the different stages slightly varies, and similar results were obtained for the deinsertion peaks during the anodic scan $\left(D_{1}=1.06 \times 10^{-14} \mathrm{~m}^{2} / \mathrm{s}, D_{2}=1.24 \times 10^{-14} \mathrm{~m}^{2} / \mathrm{s}\right.$ and $D_{3}=1.17 \times 10^{-14} \mathrm{~m}^{2} /$ $S$, respectively). 


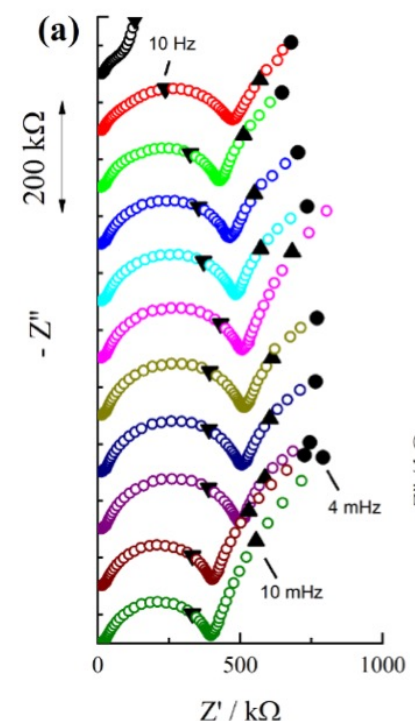

(d)

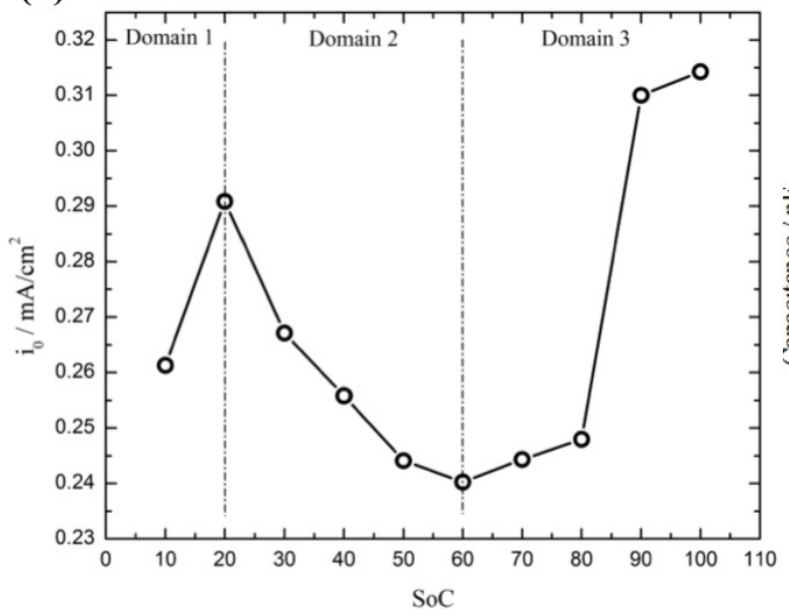

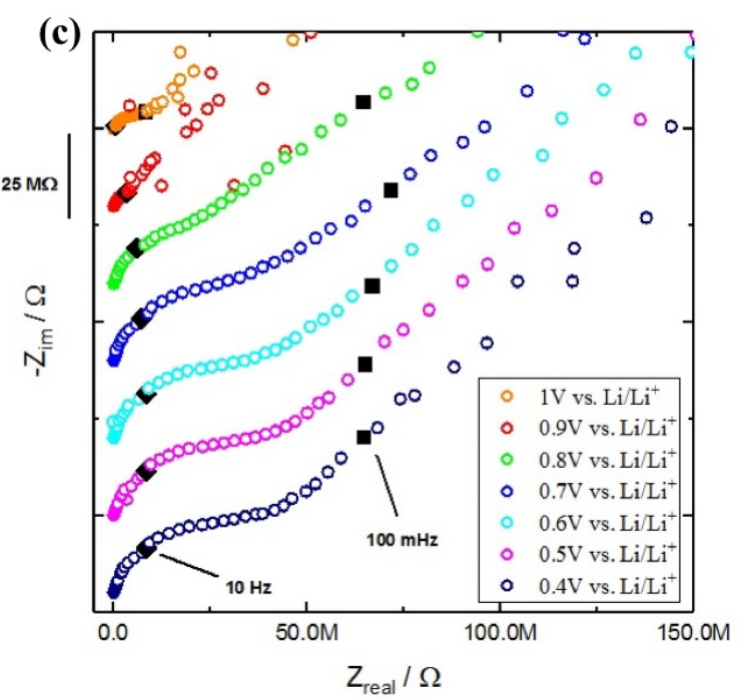

(e)

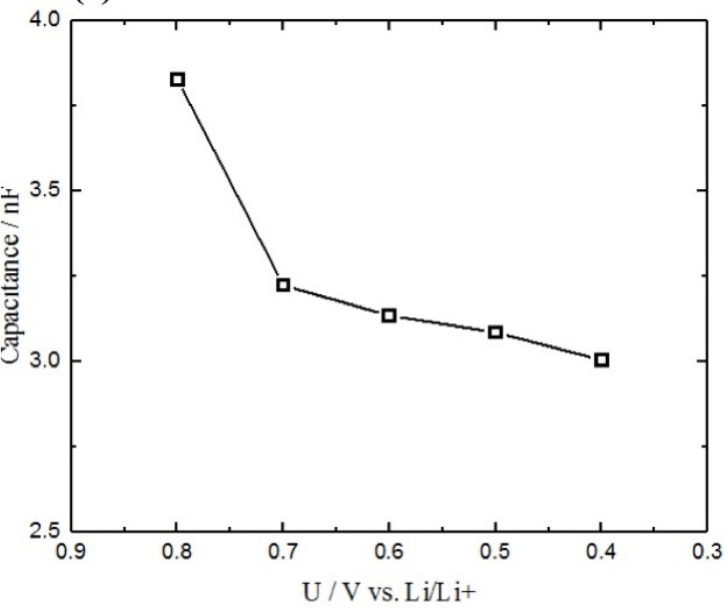

Figure 3. (a) EIS performed on the powder microelectrode as a function of the state of charge (SoC); (b) Zoom on the highfrequency domain for a 50\% SoC; (c) EIS performed on a powder microelectrode during the formation of the SEl; (d) Evolution of the exchange current density with the SoC; (e) Evolution of the capacitance of the SEI with the SoC.

\section{- Electrochemical impedance spectroscopy experiments}

EIS studies were performed as a function of the state of charge (SoC) of graphite (Fig. 3a). The $0 \%$ SoC corresponds to the graphite particles completely delithiated. These experiments were performed following a CV curve at $5 \mu \mathrm{V} / \mathrm{s}$, and then the SoC of the system was galvanostatically controlled by performing charge/discharge experiments at $\mathrm{C} / 10$ rate. Once the SoC is larger than $10 \%$, a usual impedance response is observed with a depressed loop in the high frequency region corresponding to the capacitive contribution of the SEI and the charge transfer reaction (which varies with the $\mathrm{SoC}$ ) and a lower frequency time constant ascribed to the diffusion of lithium 
inside the particles and in solution. The impedance response for a $0 \%$ SoC distinguishes from others and corresponds to the SEI response, which behaves as a capacitance in the whole frequency domain. Additionally, the $45^{\circ}$ straight-line in the high frequency domain is ascribed to the porosity of the system. Indeed, whatever the SoC, two lines with different slopes are observed in the very high frequencies, showing that the system exhibits two different porosity levels as shown on Fig. 3b. From an electrical point of view, such a behavior can be described by a branch structure of a porous electrode $[25,26]$.

The powder microelectrode also allows to study the formation of the SEI (Fig. 3c). It is shown that the impedance increases because of the growth of the SEI film. The high frequency flattened loop is ascribed to the charge transfer reaction (SEI formation) in parallel to the dielectric properties of the layer, whereas the low frequency domain is ascribed to the Warburg diffusion.

From the detailed analysis of the EIS spectra (Figs. 3a and c), the exchange current density $i_{0}$ of the insertion reaction as a function of the SOC and the interfacial capacitance ascribed to the SEI can be readily obtained. Interestingly, $i_{0}$ varies with the SoC (Fig. $3 \mathrm{~d}$ ) defining 3 main domains corresponding to the main domains observed by cyclic voltammetry (Fig. 2a). However, compared to the values reported in the literature, a difference of one order of magnitude is obtained for $i_{0}[27,28]$. This can be explained by several reasons, including the fact that the kinetic characterization of graphite has been performed without additive and that for the evaluation of $i_{0}$, the specific area of graphite is required. For the latter, whatever the technique, it is based on the assumption of a uniform distribution of particle size.

Regarding the variation of the capacitance of the SEI (Fig. 3e), it can be seen that it decreases with lower potentials. Such a behavior can thus be linked directly to the growth of the SEI.

\section{Conclusions}

The electrochemical response of graphite material without any additive has been performed with the use of a powder microelectrode. CV curves at low scan rates allowed the standard potentials for the lithiation of graphite (without additive), and the diffusion coefficient of lithium inside graphite to be determined. SEM images clearly show the formation of SEI around the graphite 
particles after cycling. The EIS response of the pure graphite as a function of the SoC has also been reported, allowing the determination of the exchange current density as well as the evolution of the capacitance of the SEI during its formation. The powder microelectrode is thus an efficient tool to study both graphite upon cycling and SEI formation. A deeper analysis of the EIS spectra is under progress for a detailed analysis of the EIS response through the porous electrode theory.

\section{References}

1. Nitta, N., et al., Li-ion battery materials: present and future. Materials Today, 2015. 18(5): p. 252264.

2. Nishizawa, M. and I. Uchida, Microelectrode-based characterization systems for advanced materials in battery and sensor applications. Electrochimica Acta, 1999. 44(21-22): p. 3629-3637.

3. Kanamura, K., et al., Electrochemical Evaluation of Active Materials for Lithium Ion Batteries by One (Single) Particle Measurement. Electrochemistry, 2016. 84(10): p. 759-765.

4. Palencsár, A. and D.A. Scherson, Electrochemical and In Situ Optical Characterization of Single Micrometer-Size Particles of Spherical Nickel Oxide in Alkaline Aqueous Electrolytes. Electrochemical and Solid-State Letters, 2003. 6(4): p. E1.

5. Nishizawa, M., et al., lon- and electron-transport properties of a single particle of disordered carbon during the lithium insertion reaction. Journal of Physical Chemistry B, 1999. 103(24): p. 4933-4936.

6. Nishizawa, M., H. Koshika, and I. Uchida, Microelectrode techniques for in situ measurements on electrical conductance of a carbon particle and its composite film during electrochemical lithium insertion/extraction. Journal of Physical Chemistry B, 1999. 103(1): p. 192-196.

7. Umeda, M., et al., Electrochemical impedance study of Li-ion insertion into mesocarbon microbead single particle electrode Part 1. Graphitized carbon. Electrochimica Acta, 2001. 47(6): p. 885-890.

8. Dokko, K., et al., Electrochemical impedance study of Li-ion insertion into mesocarbon microbead single particle electrode Part II. Disordered carbon. Electrochimica Acta, 2001. 47(6): p. 933-938.

9. Uchida, I., H. Fujiyoshi, and S. Waki, Microvoltammetric studies on single particles of battery active materials. Journal of Power Sources, 1997. 68(1): p. 139-144.

10. Dokko, K., et al., Microvoltammetry for cathode materials at elevated temperatures: electrochemical stability of single particles. Journal of Power Sources, 2000. 90(1): p. 109-115.

11. Dokko, K., et al., Kinetic study of Li-ion extraction and insertion at LiMn2O4 single particle electrodes using potential step and impedance methods. Journal of the Electrochemical Society, 2003. 150(4): p. A425-A429.

12. Dokko, K., et al., Rapid evaluation of charge/discharge properties for lithium manganese oxide particles at elevated temperatures. Journal of Solid State Electrochemistry, 2002. 6(3): p. 188-193.

13. Waki, S., et al., High-Speed voltammetry of Mn-doped LiCoO2 using a microelectrode technique. Journal of Solid State Electrochemistry, 2000. 4(4): p. 205-209.

14. Dokko, K., et al., Kinetic characterization of single particles of LiCoO2 by AC impedance and potential step methods. Journal of the Electrochemical Society, 2001. 148(5): p. A422-A426.

15. Vivier, V., et al., Cavity microelectrode for studying powder materials at a high potential scan rate. Electrochemical and Solid State Letters, 1999. 2(8): p. 385-387. 
16. Yang, W.S., et al., Electrochemical studies of Li/LixMn2O4 by using powder microelectrode. Solid State lonics, 1999. 121(1-4): p. 85-89.

17. Vivier, V., et al., Cavity microelectrode for studying battery materials: application to polyaniline powder. Electrochemistry Communications, 2000. 2(3): p. 180-185.

18. Cachet-Vivier, C., et al., Electrochemistry of powder material studied by means of the cavity microelectrode (CME). Electrochimica Acta, 2001. 47(1-2): p. 181-189.

19. Come, J., et al., Electrochemical Kinetic Study of LiFePO4 Using Cavity Microelectrode. Journal of the Electrochemical Society, 2011. 158(10): p. A1090-A1093.

20. Lu, D., et al., Study on Electrode Kinetics of Li+ Insertion in LixMn2O4 (O $<=x<=1)$ by Electrochemical Impedance Spectroscopy. Journal of Physical Chemistry C, 2007. 111(32): p. 12067-12074.

21. Vivier, V., et al., A rapid evaluation of vanadium oxide and manganese oxide as battery materials with a micro-electrochemistry technique. Journal of Power Sources, 2001. 103(1): p. 61-66.

22. Merzouki, A., et al., Microelectrochemistry study of metal-hydride battery materials Cycling behavior of LaNi3.55Mn0.4Al0.3Co0.75 compared with LaNi5 and its mono-substituted derivatives. Journal of Power Sources, 2002. 109(2): p. 281-286.

23. Levi, M.D., et al., Electrochemical behavior of graphite anode at elevated temperatures in organic carbonate solutions. Journal of Power Sources, 2003. 119-121: p. 538-542.

24. Conway, B.E., Electrochemical Supercapacitors - Scientific Fundamentals and Technological Applications. 1999, New York: Kluwer Academic/Plenum Publishers.

25. Shitanda, I., et al., Electrochemical Impedance Simulation of Branch Structure Porous Carbon Electrode Using Transmission Line Model. Electrochemistry, 2015. 83(5): p. 335-338.

26. Itagaki, M., et al., Complex impedance spectra of porous electrode with fractal structure. Electrochimica Acta, 2010. 55(21): p. 6255-6262.

27. Chang, Y.C., J.H. Jong, and G.T.K. Fey, Kinetic characterization of the electrochemical intercalation of lithium ions into graphite electrodes. Journal of the Electrochemical Society, 2000. 147(6): p. 2033-2038.

28. Smith, K.A., C.D. Rahn, and C.-Y. Wang, Control oriented ID electrochemical model of lithium ion battery. Energy Conversion and Management, 2007. 48(9): p. 2565-2578. 